\title{
LIDAR RATIOS OF DUST OVER WEST AFRICA MEASURED DURING "SHADOW" CAMPAIGN
}

\author{
Igor Veselovskii ${ }^{1}$, Philippe Goloub ${ }^{2}$, Qiaoyun $\mathrm{Hu}^{2}$, Thierry Podvin ${ }^{2}$, Michail Korenskiy ${ }^{1}$ \\ ${ }^{1}$ Prokhorov General Physics Institute, Moscow, Russia \\ ${ }^{2}$ Univ. Lille, Laboratoire d'Optique Atmosphérique, Lille, France
}

\begin{abstract}
The lidar ratios of Saharan dust at 355 and $532 \mathrm{~nm}$ $\left(\mathrm{LR}_{355}\right.$ and $\left.\mathrm{LR}_{532}\right)$ measured over West Africa during SHADOW field campaign are analyzed. Results demonstrate that even for pure dust, the lidar ratio may present strong height dependence. The possible reasons of height dependence of lidar ratios during strong dust events are considered.
\end{abstract}

\section{INTRODUCTION}

Atmospheric dust provides significant impact on the Earth system and this impact still remains highly uncertain. The Sahara desert is the largest source region of mineral dust, so quantification of the Saharan dust optical and microphysical properties is an important contribution to the study of the Earth radiative balance. In modeling the direct aerosol effect, the vertical profiles of the extinction coefficient belong to the basic inputs. When the extinction profiles are derived from the measurements of elastic backscatter lidar, the lidar ratio (extinction to backscattering ratio) is a key parameter in data inversion. The great advantage of Raman and HSRL lidars is in their ability to provide independent measurements of aerosol backscattering and extinction coefficients. The numerous lidar stations regular profile the properties of the Saharan dust layers during their transport to Europe and North America.

The properties of dust particles are modified during transport in atmosphere, so it is important to study the dust properties in the region of origin. Such observations were performed during SAMUM-1,2 experiments in 2006, 2008 (in Morocco and Capo Verde respectively), as well as during SHADOW campaign in Senegal in 20152016 in Senegal [1-5]. However, the dust is a mixture of various minerals whose relative abundance depends on dust origin, so even near the source of origin the dust properties may present significant variations. Atmospheric dust in Africa can also contain the products of biomass burning and the local pollutions. As a result, the comparison of lidar ratios observed during different campaigns my look controversy. The averaged values of LR observed during SAMUM2 campaign, are $\mathrm{LR}_{355}=52.7 \pm 10.2$ and $\mathrm{LR}_{532}=54.2 \pm 9.6 \quad$ [3]. Corresponding averaged value of depolarization ratio at $532 \mathrm{~nm}$ is $31 \%$, indicating that heavy dust episodes were predominant. In contrast to SAMUM, where lidar ratios at 355 and $532 \mathrm{~nm}$ were close, SHADOW measurements demonstrate that in many dust episodes the lidar ratio at $355 \mathrm{~nm}\left(\mathrm{LR}_{355}\right)$ significantly exceeded $\mathrm{LR}_{532}$, which was related by Veselovskii et al. [2] to increase of the imaginary part of the refractive index in UV. In our presentation we analyze vertical variation of the lidar ratios and consider relationship between $\mathrm{LR}_{355}$ and $\mathrm{LR}_{532}$ for different dust episodes.

\section{EXPERIMENTAL SETUP AND RESULTS OF THE MEASUREMENTS}
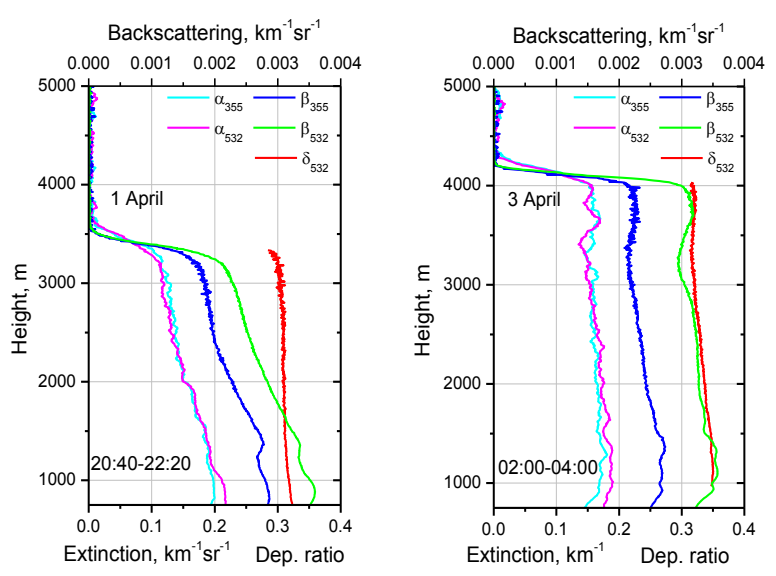

Figure 1. Vertical profiles of aerosol backscattering and extinction coefficients at $355 \mathrm{~nm}$ and $532 \mathrm{~nm}$ together with particle depolarization ratio $\delta_{532}$ for 1 April (20:40-22:20 UTC) and 3 April (02:00-04:00 $U T C)$. 
The instrumentation site is located at Mbour, Senegal. The observations were performed during March-April 2015 and December 2015-January 2016. Detailed information regarding the SHADOW campaign and the instruments is presented in [2]. The LILAS lidar is based on a tripled Nd:YAG laser with a $20 \mathrm{~Hz}$ repetition rate, and pulse energy of 90/100/100 $\mathrm{mJ}$ at $355 / 532 / 1064 \mathrm{~nm}$. The aperture of the receiving telescope is $400 \mathrm{~mm}$. The lidar allows evaluation of three particle backscattering $(355 \mathrm{~nm}, 532 \mathrm{~nm}$, $1064 \mathrm{~nm})$ and two extinction coefficients (355 $\mathrm{nm}, 532 \mathrm{~nm})$. To improve the system performance at $532 \mathrm{~nm}$, the rotational Raman channel was used instead of the vibrational one.

\subsection{Dust episode on 1-4 April 2015}
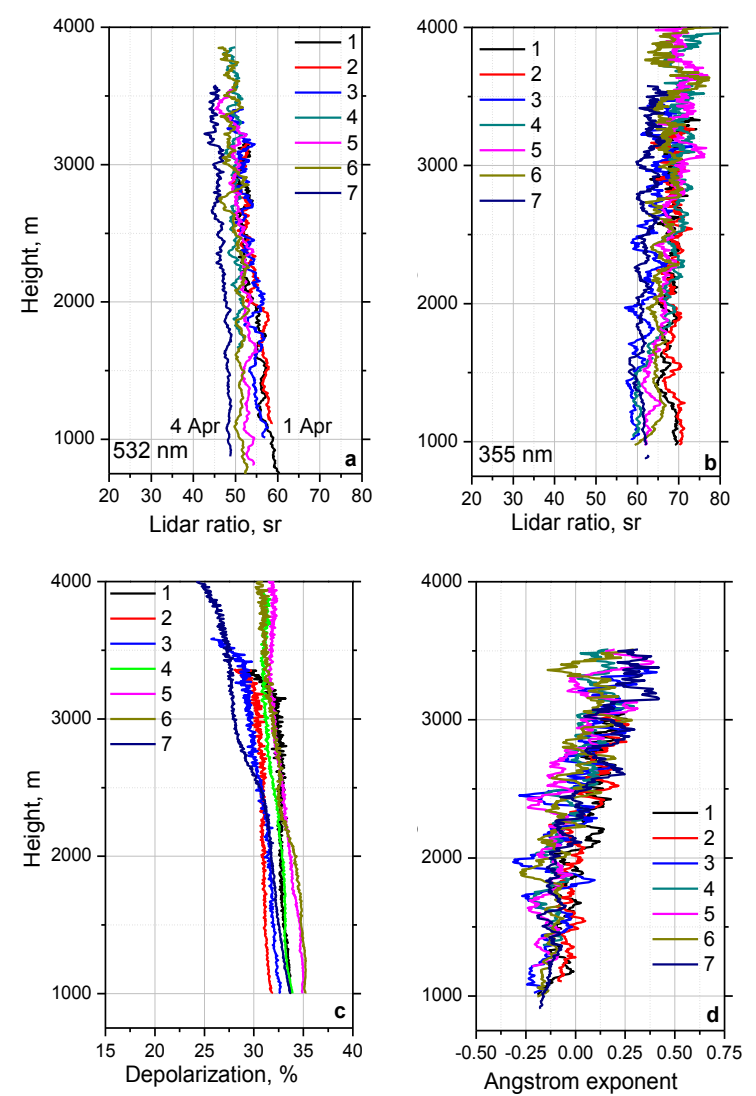

Figure 2. Vertical profiles of $(a, b)$ the lidar ratios at $355 \mathrm{~nm}$ and $352 \mathrm{~nm}$, (c) the particle depolarization ratio $\delta_{532}$ and (d) extinction Angstrom exponent at 355$532 \mathrm{~nm}$ for seven temporal intervals during 1-4 April period.

For period 1-4 April 2015 a strong dust episode occurred. Fig.1. shows vertical profiles of aerosol backscattering $\beta$ and extinction $\alpha$ coefficients at
$355 \mathrm{~nm}$ and $532 \mathrm{~nm}$ together with particle depolarization ratio $\delta_{532}$, obtained during two measurements sessions on the nights 1-2 and 2-3 April. For both sessions $\delta_{532}$ exceeds $30 \%$, and depolarization presents small decrease with height. The values $\alpha_{355}$ and $\alpha_{532}$ are close, while $\beta_{355}$ exceeds $\beta_{532}$, which can be related to increase of the imaginary part $m_{I}$ of the refractive index of dust at $355 \mathrm{~nm}$, as discussed in [2].

Fig. 2 shows profiles of lidar ratios at $355 \mathrm{~nm}$ and $532 \mathrm{~nm}$ for seven temporal intervals during 1-4 April sessions. At $1000 \mathrm{~m}$ height the $\mathrm{LR}_{532}$ decreases from $60 \mathrm{sr}$ on 1 April to $50 \mathrm{sr}$ by 4 April. Moreover, for all days lidar ratios at 532 $\mathrm{nm}$ decrease with height, reaching the value of 45 sr at $3500 \mathrm{~m}$ on 4 April. $\mathrm{LR}_{355}$ varies from 60 to $70 \mathrm{sr}$ at $1000 \mathrm{~m}$ and, in contrast with $\mathrm{LR}_{532}$, it rises with height, reaching $70 \mathrm{sr}$ at $4000 \mathrm{~m}$. The depolarization ratios for all sessions are above $30 \%$ and only on 4 April $\delta_{532}$ is below $30 \%$ near the top of dust layer. We should recall, that accuracy of calibration of depolarization measurements is about $15 \%$, so day-to-day variations of depolarization can be partly due to uncertainty of calibration procedure. The Angstrom exponent is slightly negative ($0.15 \pm 0.1)$ at low heights, but it starts rising above $2000 \mathrm{~m}$, indicating that particles become smaller.

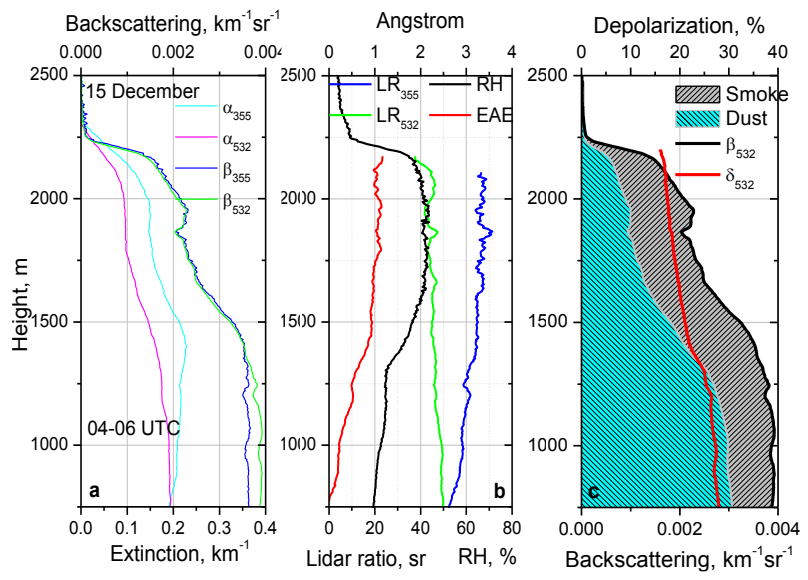

Figure 3. Vertical profiles of (a) extinction and backscattering coefficients at 355 and $532 \mathrm{~nm}$, (b) lidar ratios, Angstrom exponent and relative humidity, (c) particle depolarization and decomposition of $\beta_{532}$ for dust and smoke contributions.

One of possible explanations of observed height dependence of the particle intensive parameters is that at high altitudes the dust particles are mixed 
with another type of aerosol. The MERRA-2 aerosol transport model predicts, that for period considered the particles of organic carbon (main component of biomass burning aerosol) may occur above $2000 \mathrm{~m} \mathrm{[4].} \mathrm{Organic} \mathrm{carbon} \mathrm{(OC)} \mathrm{is}$ characterized by increased absorption in UV, which could explain the increase of $\mathrm{LR}_{355}$. Presence of small OC particles could also explain the increase of the Angstrom exponent. However, for explanation of $L_{532}$ decrease with height we should assume that $\mathrm{LR}_{532}$ of $\mathrm{OC}$ is low. This may look unexpected, because lidar measurements usually provide high values of $\mathrm{LR}_{532}$ for the smoke (above $60 \mathrm{sr}$ ). We should keep in mind however, that our measurements were performed at condition of low relative humidity (below $30 \%$ ).

\subsection{Dust-smoke episodes}

To analyze the values of lidar ratio of $\mathrm{OC}$ and their dependence on the relative humidity $(\mathrm{RH})$, we have considered several smoke episodes during the campaign. The maximal value of $\mathrm{RH}$ in these episodes varied from $30 \%$ to $90 \%$. The results obtained on 15 December 2015 are shown in Fig.3. The figure presents the lidar ratios at 355 and $532 \mathrm{~nm}$ together with profile of $\mathrm{RH}$, calculated from lidar derived water vapor mixing ratio and radio sonde measured temperature. Maximal value of $\mathrm{RH}$ is below $40 \%$. The $\mathrm{LR}_{532}$ and $\mathrm{LR}_{355}$ are close at $1000 \mathrm{~m}$, but $\mathrm{LR}_{532}$ decreases with height from $50 \mathrm{sr}$ to $40 \mathrm{sr}$, while $\mathrm{LR}_{355}$, in opposite, increases up to $70 \mathrm{sr}$.

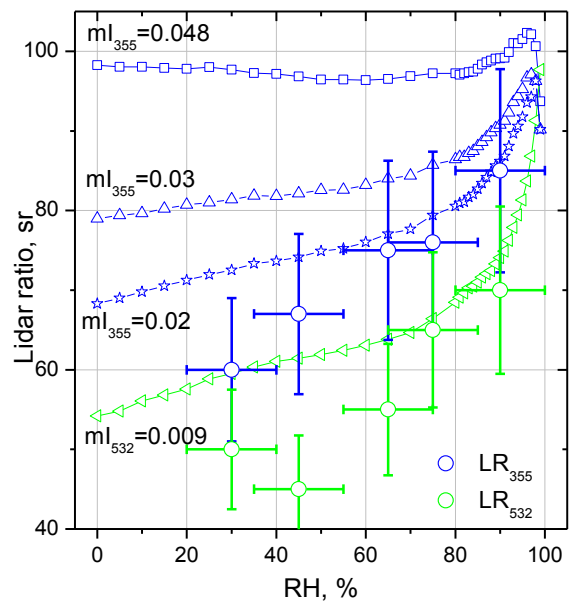

Figure 4. Lidar ratios $L R_{355}$ and $L R_{532}$ for five dustsmoke episodes (open symbols) together with simulated values (line + symbols). In simulation, three values of imaginary part of dry particles at $355 \mathrm{~nm}$ are considered: $m_{I}=0.048,0.03$, and 0.02 .
Assuming, that depolarization ratio of dust and smoke are known (35\% and 7\% correspondingly) the backscattering $\beta_{532}$ can be decomposed for dust and smoke contributions [5], as shown in Fig.3c. The contribution of smoke to $\beta_{532}$ becomes predominant above $2000 \mathrm{~m}$, and corresponding value of $L^{2} R_{532}$ is about 40 sr. For other dust smoke episodes characterized by higher $\mathrm{RH}$, the values of $L^{2} R_{53}$ and $L_{355}$ are higher. Fig. 4 shows dependence of lidar ratios on $\mathrm{RH}$ for five smoke episodes. Results are given for altitudes corresponding maxima of $\mathrm{RH}$, where smoke contribution is predominant. The same figure shows the results of simulation, using parameters of OC from MERRA-2 model [4]. In simulation we considered three values of the imaginary part of dry particles at $355 \mathrm{~nm}: \mathrm{m}_{\mathrm{I}}=0.048,0.03,0.02$. For $532 \mathrm{~nm}$ only one value $\mathrm{m}_{\mathrm{I}}=0.009$ was used. We should keep in mind, however, that smoke particles in different episodes may have different composition, so their properties depend not only on $\mathrm{RH}$. For $\mathrm{RH}>70 \%$ the measured lidar ratios are in reasonable agreement with modeling (for $\mathrm{mI}_{355}=0.02$ ), however for low $\mathrm{RH}$ the observed lidar ratios are smaller than modeled ones for both wavelengths.

\subsection{Dust episode on 10-24 April 2015}

Strong dust episode occurred also for period 1024 April. Fig.5 shows extinction coefficients and lidar ratios at 355 and $532 \mathrm{~nm}$ for two sessions on 15-16 and 23-24 April. The depolarization ratio for both days is about $30 \%$, so particles can be considered as a pure dust. Still, in contrast with 14 April episode, $L^{2} R_{35}$ and $L_{532}$ are close, which can be an indication that absorption in UV is lower. To analyze the difference in dust origin, Fig.6 presents the back trajectories for 2 April (00:00 UTC) and 24 April (01:00 UTC). In first case, air mass arrives from North - East of Sahara. For second case, the origin of air mass above $1000 \mathrm{~m}$ is shifted more to the South. Close values of lidar ratios at 355 an $532 \mathrm{~nm}$ were observed for all sessions during this dust episode. It is possible, that difference between $L_{35}$ and $\mathrm{LR}_{532}$ for considered dust episodes is related to different mineralogy in the regions of dust origin. 

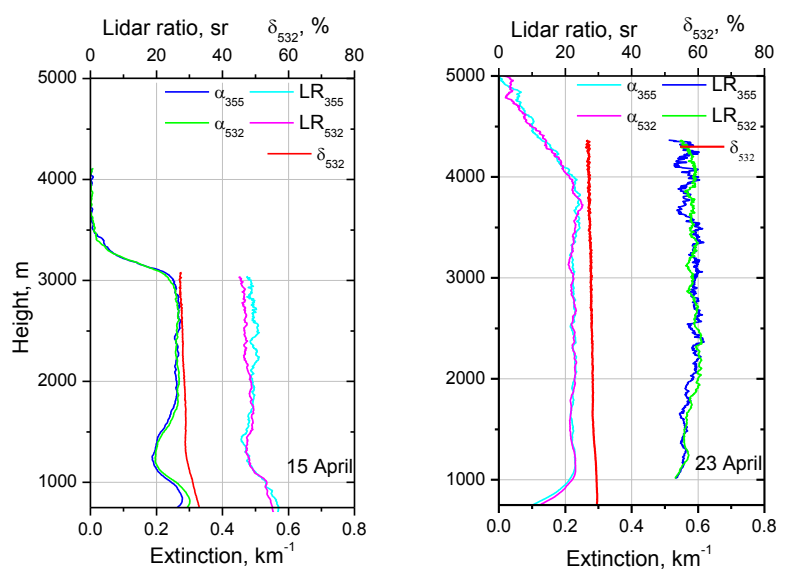

Figure 5. Vertical profiles of extinction coefficients and lidar ratios at 355 and $532 \mathrm{~nm}$ together with $\delta_{532}$ for the nights 15-16 and 23-24 April 2015.

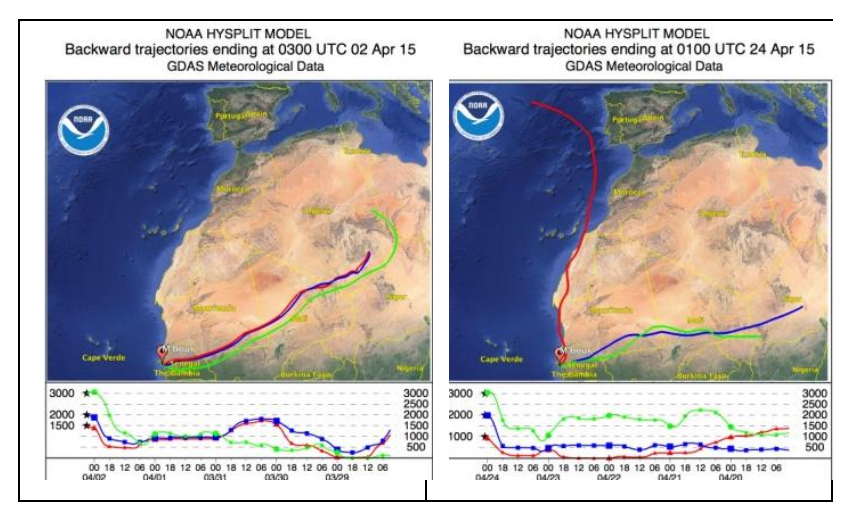

Fig.6. Back trajectory analysis for 2 April (00:00) and 24 April (01:00).

\section{CONCLUSIONS}

Presented results demonstrate that lidar ratio at $532 \mathrm{~nm}$ during dust episodes may decrease with height, which can be due to two reasons: presence of smoke near the top of the dust layer and height variation of the dust properties (in particular height variation of the imaginary part). Analysis of smoke episodes show that the lidar ratio of smoke depends on RH and varies from 40 to $70 \mathrm{sr}$ at $532 \mathrm{~nm}$. This confirms that smoke can contribute to the decrease of observed $\mathrm{LR}_{532}$ at condition of low humidity.

Observations demonstrate also that for some dust events the lidar ratios at $355 \mathrm{~nm}$ and $532 \mathrm{~nm}$ coincide, while for other episodes $L_{355}$ significantly exceeds $L_{532}$. Such difference, in principle, can be the result if different mineralogy at the region of dust origin.

\section{ACKNOWLEDGEMENTS}

The authors are very grateful to the labex CaPPA for supporting this study. Development of the software for lidar data analysis was supported by the Russian Science Foundation (project no.1617-10241).

\section{References}

[1] Ansmann, A., Petzold, A., Kandler, K., Tegen, I., Wendisch, M., Müller, D., Weinzierl, B., Müller, T., Heintzenberg, J.: Saharan Mineral Dust Experiments SAMUM-1 and SAMUM-2: what have we learned?, Tellus, 63B, 403-429, 2011.

[2] Veselovskii, I., Goloub, P., Podvin, T., et al.: Study of African dust with multi-wavelength Raman lidar during the "SHADOW" campaign in Senegal, Atm. Chem. Phys. 16, 7013-7028, 2016.

[3] Tesche, M., Groß, S., Ansmann, A., Müller, D., Althausen, D., Freudenthaler, V., and Esselborn, M.: Profiling of Saharan dust and biomass-burning smoke with multiwavelength polarization Raman lidar at Cape Verde, Tellus B, 63, 649-676, 2011.

[4] Veselovskii, I., P. Goloub, T. Podvin, et al.: Characterization of smoke/dust episode over West Africa: comparison of MERRA-2 modeling with multiwavelength Mie-Raman lidar observations, AMT 11, 949-969, 2018.

[5] Tesche, M., Ansmann, A., Müller, D., Althausen, D., Engelmann, R., Freudenthaler, V., and Groß, S.: Vertically resolved separation of dust and smoke over Cape Verde using multiwavelength Raman and polarization lidars during Saharan Mineral Dust Experiment 2008, J. Geophys. Res., 114, D13202, doi:10.1029/2009JD011862, 2009. 